\title{
'Courage to be Dislike': Strategies and Approach of Insta-Poetry in Digital Era
}

\author{
Muhammad Adek ${ }^{1}$, Dadi Satria ${ }^{2}$ \\ \{marximalize@ fbs.unp.ac.id ${ }^{1}$, dadisatria28@gmail.com ${ }^{2}$ \} \\ ${ }^{1,2}$ Universitas Negeri Padang, Padang, West Sumatra, Indonesia
}

\begin{abstract}
Heavy criticism continues to come along with the popularity of Instagram-media based poetry (further 'Instapoetry') pioneered by Lang Leav through the work Love and Misadventure (2014). A lot of appreciation or praise for similar works is considered as an impairment of the intellectualism and craftmanship for poet due to the poetry landscape that relies on accessible and honest. The classic formulation of poetry as the best choice of words in the best composition is immediately destroyed by the presence of poetry written in the language of simplistic writing. Therefore, it is necessary to investigate the quality of Lang Leav's works as a demand and accountability for literary criticism. By using a formalism approach that focuses on the three intrinsic elements of this poem (diction, syntax, stylistics), hence it is found that Leav's poems do not carry out extreme reforms which deny the classical formulation of poetry. Leav conducted a series of innovations in the form of strategies and approaches which were adjusted to the spirit of the age so that her works could be accepted in the wider community.
\end{abstract}

Keywords: insta-poetry, digital era, lang leav, formalism

\section{Introduction}

The terminology of "digital era" within the literature domain has not been bound by a strong red thread ${ }^{[1][2] . ~ T h e ~ o p i n i o n ~ o f ~ l i t e r a r y ~ c r i t i c s ~ t h a t ~ i s ~ q u i t e ~ r e l e v a n t ~ t o ~ t h i s ~ p r o b l e m ~ i s ~ F r e d e r i c ~}$ Jameson in his thesis work entitled The Cultural Logic of Late Capitalism [3]. In his book, Jameson divided the literary period in step with the period of development of capitalism into three phases (based on Mendel's tripartite model) ${ }^{[4]}$, namely the phase of the steam engine (middle of the 19th century), the electrical phase (late 19th century) and the nuclear-electronic phase (mid-20th century). These three phases also eventually gave birth to three iconic literary phases namely realism, modernism and postmodernism.

The digital age could be considered as the 'advanced phase' (or fourth phase) of the period of capitalism offered by Jameson above recently popular as the Industrial Revolution 4.0. Unstoppable progress on the advancement of intelligence, innovation and human productivity is now also being transmitted into cultural products such as films, paintings and even classical literary works such as prose and poetry. Almost all cultural products undergo adjustments-or if not called-as extreme transformations due to the transfer of the medium of delivery or the field of fighting ${ }^{[5]}$. One of the cultural products that has transformed quite sharply lately is poetry.

Poetry nowadays is no longer a voice of conscience written quietly on a piece of old paper or journal book with an antique quill pen; the result of serious contemplation of lonely bohemians who for days think of a debate about themselves or their surroundings. The present century no longer allows such outmoded creative processes to take place again and slowly begins to be replaced by the digitization process ${ }^{[6]}$. This digital time demands openness, 
experimental ideas, subjective opinions and globalization of a work ${ }^{[7]}$. Poetry as a cultural product ultimately succumbs to the cultural logic of the fourth phase of capitalism.

Therefore, the occurrence of "Insta-poetry" (poetry published on Instagram platform) as per cross-breeding between the demands of the digital age and the existence of poetry as a cultural product of the advanced phase of capitalism is inevitable. This new color poem is growing rapidly and reaching a wider audience of creations that have previously existed. In this digital era, poetry made a big leap in terms of reception and market ${ }^{[8]}$. Poetry is no longer synonymous with a sacred ritual, which is performed by certain people with a high degree of difficulty. In other words, poetry is considered to have undergone a significant democratization process lately [9].

We can see the large stream of poetry's acceptance from the trends seen in social media as an open digital field ${ }^{[10],[11]}$. Numbers and statistics also show the same signs where poetry book sales have jumped significantly after decades ${ }^{[12]}$. This great potential and vibe seems to revive poetry from prolonged sluggishness and make it as a coca-cola in a celebration of contemporary literature. Poetry won back its fame like the period of Renaissance or romanticism in the past centuries.

However, not all parties consider 'Poetry Renaissance 2.0' as a breath of fresh air. Literary critic, Rebecca Watt wrote an article to criticize the phenomenon with a fairly tendentious title, The Cult of the Noble Amateur ${ }^{[13]}$. Watt highlighted several important points related to the recent explosion of "insta-poetry" bombs. For example Watt questioned the craftmanship weakness of "insta-poetry" through a fairly bold statement: “... artless poetry sells." Watt also regretted the permissiveness of some literary retainers and institutions towards the cult of "instapoetry". He considered those actions as intellectual degradation and negation on the craft of poets.

Referring to the problem above, this study seeks to provide a deeper study of Insta-poetry. This paper will limit the discussion to a collection of poems written by Lang Leav which is considered by The Guardian as a pioneer and role-model of the insta-poetry movement that has overwhelmed the whole world ${ }^{[14]}$. The selection of Leav was also based on the recognition of the glory of his works also reflected in several prestigious awards: a Qantas Spirit of Youth Award, Churchill Fellowship and Goodreads Reader's Choice Award.

In-depth analysis of the poetic elements at concerning issue such as 'honesty' and 'accessibility' in relation to criticism of poetry literature is performed as a responsibility for the quality of a work. The discussion session will link this phenomenon to the context of the digital age that lies behind and influences this excessive shifting.

\section{Method}

Leav's book collection of poetry entitled Love and Misadventure ${ }^{[15]}$ is a material object in this study. The script is filled mostly with bite-sized poems that are written modestly and visually pleasing. For the most part, each page has only a single poem; there are a very few poems that covers full-paged. In every beginning of the section, it is featured by pencil sketch that depicts young female figures with balloons and puppies. To fully-comprehend the text as a simulation of analysis, the result of reading is followed by identification, categorization, investigation and rationalization.

Referring to the roots of polemics and insistent criticism of the form of Insta-poetry, the formal object of the study is formalism. Formalism puts the text as the soul of a literary work [16]. The combination and harmony of the poetic elements (parallelism) composing a poetic text is absoluteness that cannot be bargained for. The pioneers of formalism, T.S Elliot and I. A. 
Richard considers that 'art must be treated as art and things outside of it such as sociological and historical aspects will only damage particular emotion from the work' ${ }^{[17]}$. Therefore, the only way to reach the best understanding and judgment from a literary work is through seeing the interrelationships of the building elements of poetry starting from elements such as sound function, word order, organization of language material, expressions and combinations in the text.

Concerning the issue of 'honesty' and 'accessible which are the trademarks or fundamental differences in Insta-poetry with other kind of poems, then this assessment is conducted by relating the surface structure and deep structure. The 'accessible' factor refers to the surface structure which can be examined through the empowerment of diction and syntactic innovation. The 'honesty' factor can be tested through the placement of point of view, certainty of character identity, and clarity of the theme.

\section{Finding and Discussion}

Based on the formulation of predetermined problem, the results that can be submitted is Leav (the author) applies certain techniques to emphasize "accessible" and "honesty" aspects in her insta-poetry so that her work has a distinctive character. The discussion on the application of those expertise will be presented as follows.

\subsection{Accessible}

In an effort to assist the reader in the process of understanding her work, Leav applies three particular techniques which can be identified through morphological aspects, syntactic aspects and stylistic aspects.

\subsubsection{Strong-ties diction}

\section{a. Based on Nowadays Cultural Trend}

Until 2010s, poetry is claimed to have long lost allure in the midst of the reading community, mostly by the younger generation ${ }^{[18]}$. One factor that might be pointed out is the lack of connection between these poems and the world of casual readers. Leav and other Insta-poet artist realized and tried to cover the gap through infiltration of references that were close to the current readers until finally his poems were easily digested and accepted ${ }^{[19]}$.

For example, in the poem entitled "Impossible Task", Leav did intertextualism with one of the world's greatest works, "Hamlet" through utterance to try or untry. With this clue, the reader will be very easy to digest the phrase because the pattern of this expression is rooted in one of the most popular expressions in literary world. Like other fields of art, this imitation-practice is positively acceptable.

Similar technique is repeated while using the phrase 'time-travelers' which is known and popularized by the novel H.G. Well's The Time Machine (1985). This term developed to one of the concepts that was very well-know in the development of popular culture to date. Some famous contemporary films that present time travel formulas are Terminator, Back to the Future, The Time Traveler's Wife, X-Men, Star-Trek, Avengers, and Doraemon.

Besides standing on shoulder of the giants of the pop culture world, Leav also attaches her works tenaciously to vocabulary words that are often occured in contemporary eminent-song lyrics. As for some examples; tic-tac-toe (Drake and Nicky Minaj), photograph (Ed Sheeran), fireworks (Katy Perry), circus (Britney Spears), rooftops (Lost Phrophet) carousel (Blink 182). 
These vocabularies are like puzzle debris that are ready to be attached to the frame of Leav's poetry.

Not just only borrowing from a collection of pop culture, but Leav also conducts experiments fairly frequent in fabricating the diction. The dominant technique of mixing diction is the assimilation of ordinary vocabulary with concepts commonly found in modern civilization. This can be found in the following data: turbulent turn (A Lover's Past), spark of static (Solo Show), question mark (Canyons), written in traffic (Written in Traffic), and major catastrophe (Rogue Planet). These wordlists do not require the reader to look at the glossarium and will immediately be able to capture messages from Leav's poems.

Leav is certainly a poet who belong to modern age. Therefore she also tried to present the spirit of modern civilization in her poetry. In addition to being presented through explicit expressions, Leav explicitly includes the existed-problems of modern times which are also felt by most readers. The phrase 'Sunday with Michael' is an emphasis on something different/special with Sunday. The definition of Sunday in this century has been very different from previous centuries. Sunday now is considered a small gift because current life only allocate limited time to rest and refresh in the midst of the insistence of daily tasks.

Similar case with the phrase 'feel like home' that hints at the anxiety of rising generation who feel homesick due to the demands of huge task. Leav is also sensitive to the dreams of the younger people who want to go adventure in wild nature because of the congestion facing the routine urban atmosphere. This is manifested in the phrase 'sail in waters' (a Voyage).

\section{b. Nowadays Lingual Attitude}

Besides being skilled in combining word materials that are easily found and identified in digital era, Leav also implements a modest composition technique in compiling her poetry. Leav in this pieces adapts the spirit of the digital age where efficiency is a key. The complexity caused by a large flow of information, endless work, accumulation of big stuffs and other abundances make people easily exhausted and distracted in facing a situation ${ }^{[20]}$. To overcome this spectacle, Leav offers the experience of reading poetry with a linguistic approach that adopts the spirit of computer age.

Some examples of data showing this point are the intensive usage of the prefix "un-" as stated in: my undoing; undo; un-sing (a Betrayal); untry (Impossible Task); un-feel (After You); unseeing eyes (a Reverie). The prefix "un-" in the examples above serves as 'a negation of a concept, condition or process'. This over-generalized and simplification technique also appear in other forms but still convey the same goal. These are occurred suchlike: sadness, madness, goodness, badness (Written in Traffic); no ending, no said good-bye (Closure); no right to feel (Just Friends); no song for (Love Lost), no longer knew (a Dream).

In the realm of authorship (both creative and academic), there is an unwritten rule that states the prohibition on using excessive adverb. Mark Twain once said that adverb was the weapon of a lazy writer. The excessive use of adverb will leave many understanding gaps that must be filled by the reader in achieving the intent of poets, which of course is not efficient at all. In line with the spirit of the era that requires efficiency in all aspects, the limited use of adverb is a wise choice. Leav takes this rule cautiously by presenting adverb sequentially only twice: gentlyprofoundly (Lost and Found), and tentatively-passionately-tenderly (Beautiful). The sequential arrangement above can certainly be understood as creating rhyme. 


\section{c. Nowadays Romantic Diction}

There is no more universal topic than love. The bitter-sweet theme of a couple's love story in Leav's poetry has been clear since its title. Many writers regularly present this multiinterpretation love-theme. However, Leav strongly emphasizes her poem only about the love of young couple in present-day. Leav clearly talks about it and creates a very tight association in the reader's head through long-known romantic diction such as: first love, fell in love, skies settings, singing birds, good night, good luck, saving you, fairy tale, love letters, swan song, yours, mine, songs-sings-dream, solitary, fear and faith \& hope and despair.

\subsubsection{Consistent syntax}

The arrangement of words in poetry is vitally sacred as emphasized many times by the romantic poet William Worthwords. Leav in her work also agreed on the formula proposed by her predecessor poet. Leav seems to consider every weight and composition of each word of her poetry lines. For example in the poem "A Toast", Leav applies the same formulation in constructing the body of poetry.

\section{To new beginnings, in fear and faith and all it tinges.}

To love is a dare, when hope and despair, are gates upon it hinges.

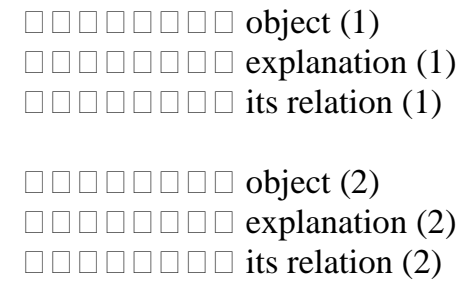

Figure 1. The syntactical pattern based on enjambment function (1)

Leav truly utilizes the enjambment function efficiently. The repetition assists the readers to rapidly identify the function and relationships between the lines. In the end, it also helps the reader in the process of understanding comprehensively. In another example in the poem entitled "Xs and Os", Leav also replicate the use of the enjambment function to build a poetic framework.

$$
\begin{aligned}
& \text { Love is a game } \\
& \text { of tic-tac-toe, } \\
& \text { constanly waiting, } \\
& \text { for the next } X \text { or } O
\end{aligned}
$$

object (1)

explanation (1)

explanation (1)

its relation (1)

Figure 2. The syntactical pattern based on enjambment function (2)

Apart from linking the explanation of objects in verse, Leav also did it between stanzas. This can be found in another poem entitled "When Ignorance is Bliss":
I deplore,
$\square \square \square \square \square \square \square \square$ object (1)
being ignored.
explanation (1)
For-
object (2)
I am not a bore!
explanation (2) 


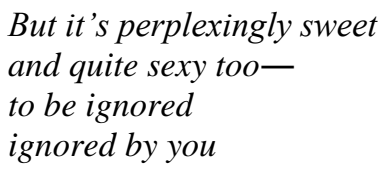

Figure 3. The syntactical pattern based on enjambment function (3)

In the broader sense, Leav continually places the object of conversation on the first line of each verse and then it is followed by explanation line. Excepting in some cases, Leav also positioned the object as a closing line as in the poem entitled "Sea of Strangers":
And nothing else
$\square \square \square \square \square \square \square \square$ explanation (1)
can take what only-
explanation (1)
was always meant
explanation (1)
as solely yours.
object (1)

Figure 4. The syntactical pattern based on enjambment function (4)

Another syntactic formulation dominantly employed by Leav is doing comparisons/ analogies between stanzas. The setup is first stanza functions as object and the next stanza as explanatory. The example can be seen in a poem called "A Voyage":

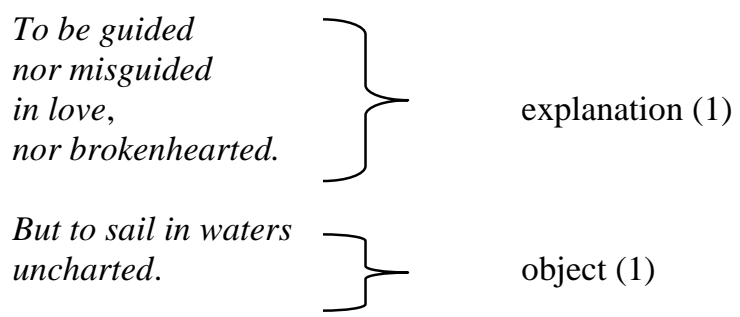

Figure 5. The syntactical pattern based on stanza comparison (1)

In other versions, Leav only provides vehicles without presenting a tenor as a reference or clarification. This form can be seen from the poem entitled "An Endearing Trait":

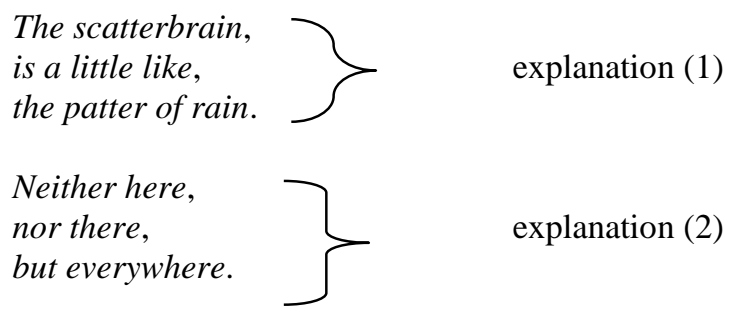

Figure 6. The syntactical pattern based on stanza comparison (2)

The identical and repetitive syntactic formulation finally forms an unconscious pattern in the reader's mind. The ultimate goal is to ease the digestive and understanding process of the 
poetry as a whole by eliminating doubt, complexity, and vagueness of vision from the structure of the poetry.

\subsection{Honest}

The second feature claimed to be one of the prominent characteristics of Leav's instapoetries is about honesty. Honesty is meant to be related to the clarity of what is discussed, the situation at hand, to who is involved in it. Based on the results of data analysis, two strategies were used by Leav to highlight this aspect as described below:

\subsubsection{Insecure young lady as the speaker}

Almost every time in reading a poem, the reader always come to the presumption that it must be the author (Lang Leav) which acts as the speaker of the story. It is not entirely true or false because readers generally assume that a work is a representative voice of the author. In Leav's poems, a young female figure (similar to Leav) is found as the main character.

This can be identified first in the introductory poem entitled "A Dedication" which mentions the presence of a female poet in she is poet and the male character she thinks about in to thought of him is her lover in and he is her poetry. This claim is then reinforced by the clue illustration of a young woman with items that are identical to the world of adolescents (balloons and puppies) beginning with each chapter of the book.

After getting the main character's identity, the next task is to uncover the attitude of the character to describe the tone of the whole poem. After skipping the first and second poems (because they do not present characters), in the third poem entitled "A Dangerous Recipe" the character of a young woman was rediscovered who talks about her lover in to love him. The attitude shown by the character is insecurity. The woman feels reluctance in loving her lover to love him through the phrase I hold highly suspicious. The discomfort eventually leads to doubts and insensitivity in determining something (or choice). This is manifested in the phrase then being told, to do the dishes.

Insecurity experienced by female figures in dealing romance-problems reappeared in a poem titled "Just Friend." Insecurity appears in the form of uncertainty in an effort to get the heart of the idol's heart which is shown in the phrase perhaps i never will. Although in his heart she did not accept the situation in front of her: my anger when you're with her however, she was completely helpless: $i$ have no right to feel. The action that this female character wants to show suchlike I shouldn't feel so let down; i shouldn't show you forever will depend on the presence of the lover when you don't call; when you're around. Until finally this woman was really desperate to feel that she I've got no right to feel it.

Insecurity is not always felt as a terrible and painful experience. Sometimes, the narrator experiences it differently and even quite comfortable with the inability to reach the attention of her lover as in the poem entitled "When Ignorance is Bliss." The female character in this poem feels a pleasant sensation that she describes with the image of taste it's perplexingly sweet and quite sexy too when ignored by her lover: to be ignored by you. The bad attitude received by the lady-speaker from her lover is considered a blessing-in-disguise.

Placement of the character's standing point in a situation can also show the character's insecure attitude in dealing with her lover. In a poem entitled "Sea of Strangers", a female character positions herself as the final destination of her lover's long voyage. The lover (you) acts as an active agent described as if he spent his entire life searching for the woman: your life spent sailing to my shores. The woman also illustrates how heavy and dramatic the man's journey is in conquering herself through expression the arms ... to hold / will ache beneath / the 
heavy oars. Until the closing line, the woman assures her lover that nothing else can take her; she is the destiny that he must have obtained: was always meant as solely yours. The female figure here positioned herself as the winner's prize which is contested by aggressive men and normalizing submissive behavior is a matter of pride.

Not only when dealing with her lovers, but also when alone the woman-speaker also never felt really assured. In a poem entitled "Afraid to Love", a female character completely closes herself $i$ turn away and close my heart from a 'game' of love (see poems Xs and Os). This is caused by experiences gained from the past: for the past has taught; the thing I've done. Until finally she did not have the courage anymore and she was confined to the the feeling: afraid to love.

In other poems, the speaker's insecurity appears in the form of self-portrayals like grumpy in the phrase: a flicker of a blown candle; a melancholy soul; a lonely kite; a crumple note; desperate in the phrase: you come and go so easily; mine is split into two, if you were not to wake (from sleep); $i$ can't forgive me; jealousy in the phrase: how envy is so the half of me, confusing in the phrase: i am relieved, so relieved-and a little dissapointed; i'll wonder why, can i un-feel it; negative thinking in the phrase: in your hesitation I found my answer, with thought to haunt you every night.

Ironically, female character seems to accept and enjoy this situation. This behavior is represented in the "Letting Him Go" poem as a sacrifice tender. In general, every belief she decides on her own or every considered step in the opposite direction of her lover pictured like the pained in the lost song of mermaid or the broken feet of ballerina.

\subsubsection{Modern-day romantic problem}

Outside the clarity of the context and actors, the clarity of the theme also contributes significantly to the level of honesty of the work. By knowing the subject matter since the first, the readers will be greatly helped to focus their mind on just one line of conversation until finally the readers feel easy in understanding the entire poem. In presenting her poems, Leav helped and approached her readers by focusing only on the discussion about the problem of love in modern day.

The first problem offered by Leav is the complexity in love. Leav describes the matter of love as: a dare to face hope and dispute (a Toast); a constantly waiting (Xs and Os); a dangerous recipe (A Dangerous Recipe); a sacrificial tender (Letting Him Go); and it will stir, ache, disarm, makes me turn-to-blush, split you into two or drive you mad. Mixing the features above makes love more complicated to understand but also more exciting. The entire features mentioned above are twisted tightly in a complicated knot.

The second problem highlighted by Leav in her poem is about self-doubt. As discussed in the previous discussion, the main speaker in the poems is a fragile woman. The speaker's vulnerability has an impact on her actions in facing complicated love which is one of them is prolonged pessimistic feeling. In the "Just a Friend", the speaker showed it repeatedly: $i$ have no right to feel; $i$ shouldn't feel so let down; $i$ know i've no right to feel. In other forms, it appears as a feeling of being totally ignored who are exposed to the poem "His Word": what he feels for me, he never feels / $i$ am a word but has never seen; or in "the Wanderer", the speaker exposes his worthlessness in the phrase: the flicker of the candle blown; a lone lone lost in flightsomeone once had flown.

The later problem that often decorate the love story of female-speakers is the matter of sense-of-belonging. The speaker with a self-distrust issue repeatedly disputing the ownership of herself to her lover. As in the "Lost Things" poem, the speaker compares herself to: $a$ thing that is waiting to be found. Women, both conventional and modern, want to be a goal of a man's 
love journey as in the poem "Sea of Strangers": your life spent sailing to my shore. Inspired by the uncertainty exhibited by the nature of this disruptive era, no wonder the fragile femalespeakers, want to be as fast as possible to belong to somewhere or someone.

\section{Conclusion}

In general, there was no radical change from Lang Leav's efforts in redefining the genre of poetry in the digital age. Leav even tends to approve the classic formula of poetry as the best choice of words, in the best arrangement. Leav still adheres to the classic mantra in building each line of her poems. Only, Leav must innovate in adjusting strategies and approaches that match the classical formula in order to be in harmony with the spirit of the century.

As a result, the "best words" aspect was formulated by Leav in the selection of words (diction) that were acceptable to the tastes of the digital age like referring to pop-cultural trends, using current language-attitude and inserting cliché romantics. Additionally, Leav also empowers the efficiency of the point of view to help the reader understand in living the trivial experiences presented by Leav as the common people.

The "best arrangement" aspect is manifested by Leav in a simple but consistent syntactic formula. She makes patterns of reasoning that are easily identified and intimate with her reader. In this way, public readers can save their times in comprehending a complex and long cognitive proces. Thus, in the end Leav's poems can be considered as a fresh menu of contemporary literary consumption that is accesible and honest.

\section{Acknowledgements}

The author(s) disclosed receipt of the following financial support for the research, authorship, and/or publication of this article: This work was supported and funded by the Research and Community Service Council (LP2M) of Universitas Negeri Padang grant number 182/UN.35/LT/2019 fiscal year 2019.

\section{References}

[1] N. Wardrip-Fruin, "Reading digital literature: Surface, data, interaction, and expressive processing." in Siemens, R., \& Schreibman, S. (Eds.) in A Companion to Digital Literary Studies. New Jersey: John Wiley \& Sons, 2013.

[2] N. Wardrip-Fruin, "Five elements of digital literature." In R. Simanowski, Reading Moving Letters: Digital Literature in Research and Teaching. A Handbook. Bielefeld: Transcript, 2010, pp. 29-57.

[3] F. Jameson, Postmodernism, or the Cultural Logic of Late Capitalism. New Left Review, vol. 146. (July-August), 1984, pp. 53-93.

[4] E. Mandel, Late Capitalism. London: Humanities Press, 1975, pp. 387.

[5] E. T. Dresang and K. McClelland "Radical change: Digital age literature and learning." Theory into Practice, vol. 38, no. 3, 1999, pp. 160-167.

[6] C. Jewitt, Technology, Literacy and Learning: A Multimodal Approach. New York: Routledge, 2006.

[7] C. Lankshear, and M. Knobel "Do-it-yourself broadcasting: Writing weblogs in a knowledge society". Geocities. 2003. http://www.geocities.com/c.lankshear/blog2003 (accessed 17.10.04)

[8] M. Millner, "Instapoets Prove Powerful in Print." Poets \& Writers Magazine, vol. 46, no. 4, 2018, pp. 17. Gale Academic Onefile Accessed 12 Aug. 2019. 
[9] A. Stornaiuolo, G. Hull and M. E. Nelson, "Mobile Texts and Migrant Audiences: Rethinking Literacy and Assessment in a New Media Age.” Language Arts vol. 86, no. 5, 2009, pp. 382-392.

[10] K. I. Berens, E-Lit's \#1 Hit: Is Instagram Poetry E-literature? Electronic Book Review (2019).

[11] K. I. Berens, "Instapoetry Matters." English Faculty Publications and Presentations, vol. 33, 2018. https://pdxscholar.library.pdx.edu/eng_fac/33.

[12] A. Elizabeth, "For the Love of Poetry." Books+ Publishing vol. 97 no.4, 2018, pp. 10.

[13] R. Watts, "The cult of the noble amateur." PN Review, vol. 44, no. 3, 2018, p 13-17.

[14] H. Qureshi, "How Do I Love Thee? Let Me Instagram It." The Guardian. March 5, 2018. https://www.theguardian.com/books/2015/nov/23/instapoets-instagram-twitter-poetrylang-leav-rupi-kaur-tyler-knott-gregson.

[15] L. Leav, Love and Misadventures. Missouri: Andrews McMeel, 2014.

[16] V. Shklovsky, Viktor Shklovsky: A Reader. New York: Bloomsbury Publishing, 2016.

[17] P. McCallum, Literature and Method: Towards a critique of I A Richards, T S Eliot and F R Leavis. Gill \& MacMillan, 1983.

[18] National Endowment for the Arts. "1992-2012 Survey of Public Participation in the Arts" Washington DC: National Endowment for the Arts, 2015.

[19] H. A. Alghadeer, "Digital 2014 Landscapes: Rethinking Poetry Interpretation in Multimodal" Texts Journal of Arts and Humanities, vol. 3 no. 2, 2015, pp. 87-96.

[20] S. Hauw and A. Vos, "Millennials' Career Perspective and Psychological Contract Expectations: Does the Recession Lead to Lowered Expectations?" Journal of Business \& Psychology, vol. 25 no. 2, 2010, pp. 293-302.

[21] J. Wainwright, Poetry: The Basics. London: Routledge, 2015. 